\title{
Performances culturais: a invasão zumbi, a morte do sujeito e outras desorientações
}

\author{
SAINY C. B. VELOSO
}

\section{Resumo}

$\mathrm{O}$ artigo considera como indicial das performances culturais contemporâneas a proliferação em todo o mundo da temática ficcional do apocalipse zumbi, por meio das histórias em quadrinhos, jogos de tabuleiro, filmes, games, seriados para televisão, cartazes e passeatas. A partir de então, reflete a temática e analisa esse conjunto de produtos e ações, circunscrevendo a questão: a crise atual é uma crise de orientação dentro de um mundo não interpretável, tal como demonstra a invasão zumbi? Para tanto, se apoia em conceitos delimitadores das performances culturais (GOFFMAN, 2011); drama social (TURNER, 1974); cultura (GEERTZ, 1989); e crise social (JAMESON, 1984; SENNETT, 1998).

Palavras-chave:

Performances culturais, invasão zumbi, crise social 


\title{
Cultural performances: the zombie invasion, the death of the subject and other disorientation
}

\author{
SAINY C. B. VELOSO
}

\section{Abstract}

The article considers how contemporary cultural performances indicial, the worldwide proliferation of fictional theme of the zombie apocalypse, through comic books, board games, movies, games, television serials, posters, rallies. Since then, reflects the theme and looks at this set of products and actions, limited the issue: the current crisis is a crisis of guidance within a world not interpretable, as demonstrates the zombie invasion? To this end, rests on concepts of cultural

Keywords: Cultural performances, performances delimiters (GOFFMAN, 2011); social drama (TURNER, 1974); culture (GEERTZ, 1989); and social crisis zombie invasion, social crisis (JAMESON, 1997; SENNETT, 1998). 
"Darkness falls across the land The midnight hour is close at hand Creatures crawl in search of blood To terrorize y'all's neighborhood And whosoever shall be found Without the soul for getting down Must stand and face the hounds of hell And rot inside a corpse's shell" Rod Temperton, Triller, 1982.

\section{Performances culturais}

O que chamo de invasão zumbi refere-se à proliferação de histórias em quadrinhos, jogos de tabuleiro, filmes, games, seriados para televisão, cartazes, passeatas e performances com a temática zumbi. O questionamento quanto ao que perpassa essas criações e seu consumo, principalmente pelos jovens, leva-me ao pressuposto de uma identificação subjetiva e à reflexão sobre as performances culturais atuais.

Trata-se de performances culturais entendidas como encenações, modos de atuar, desempenhar um papel social, conscientemente ou não, em uma situação ou perante seus semelhantes, de modo a dar credibilidade à imagem que se quer sustentar. Uso a palavra encenar por corresponder "à encenação teatral e às técnicas para sustentação do desempenho de um ator, tal qual de um indivíduo perante seu público" (GOFFMAN, 2011, p. 9).

Estamos falando de indivíduos que representam papéis sociais, em cenários culturais, de acordo com o que se espera de sua recepção e de acordo com suas próprias ansiedades em aprender a dinâmica social. Nessa dinâmica, os elementos da tradição cênica - o palco, o ator que se apresenta sob a máscara de um personagem e a plateia - se reduzem aos 
papéis dos indivíduos determinados de acordo com os papéis desempenhados pelos outros presentes, constitutivos dessa mesma plateia (GOFFMAN, 2011).

A performance realizada pela invasão e proliferação de zumbis (figura 1) é socialmente significante como fundante de um drama com inquietações da situação vinculada à posição social dos indivíduos. É um texto performático, um conjunto de representações e ordenamentos de temas culturais que o dota de significados particulares: morte, dilaceramento, violência, fragmentação, sobrevivência, desorientação, ruptura social, medo, impotência, frustração, falta de profundidade e sentidos, ausência de subjetividade. O construto desses temas torna-os significativos quando apreendidos como tangíveis.

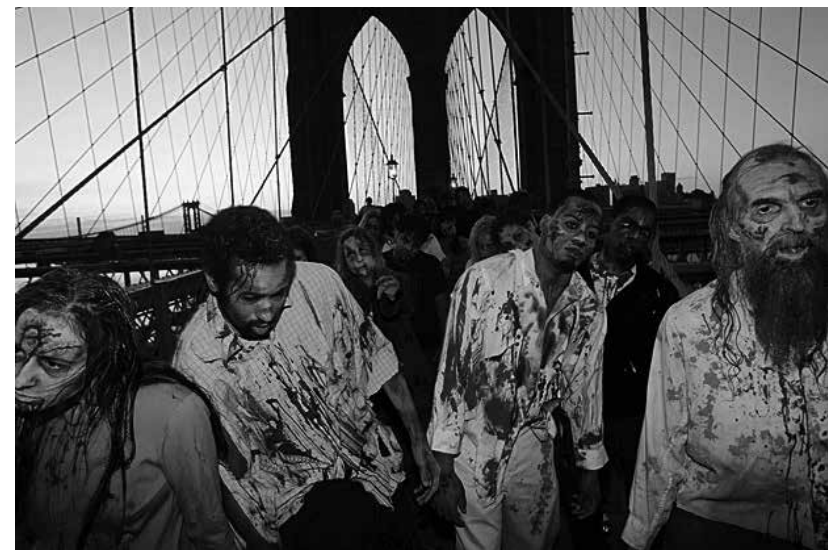

Contudo, o que chamo de invasão zumbi não é apenas um conjunto de representações visuais que me serve para articular e demonstrar significados. O que busco é um modelo de subjetividade subjacente nesse conjunto expressivo de performances culturais, de maneira que, parafraseando Geertz (1989, p. 45), abra a subjetividade do ser humano para ele mesmo. A invasão zumbi, assim como qualquer outra forma de arte, popular ou não, não são reflexos de uma sensibilidade preexistente e representada alegoricamente. Elas são agentes ativos na criação e manutenção de tal sensibilidade ou sua falta.

Na centralidade desse pensamento encontra-se um conjunto de ansiedades, diferentes, embora não desconectadas, daquelas trazidas à tona que circunscrevem as questões da irrupção da animalidade na vida humana. As performances zumbis indiciam terror, mas ao mesmo tempo fascínio por manifestações caóticas da animalidade humana e daquilo que nossa imaginação al- 
cança, sem no entanto conseguir confrontar. Manifestações que provocam perplexidade, caos, mas são interpretáveis, pois ultrapassam nossa capacidade analítica e introspecção moral.

Essas encenações indicam uma variedade de performances e teatralidades culturalmente construídas cujo valor de representação é concebido de acordo com o jogo de forças entre as estruturas culturais das instituições, poder econômico, midiático, e os fluxos energéticos individuais - subjetivos, gestuais, vocais, libidinais - atuantes nas performances, os quais geram processos instáveis de teatralidades. Instáveis quando um mesmo indivíduo realiza performances diferentes de acordo com os espaços de atuação.

Dessa maneira, penso as performances culturais não somente na operatividade do que chamamos de teatro, mas também como encenações, tramas construídas e desempenhadas por atores sociais, por meio de seus desempenhos. Tudo isso tanto representa como induz certo modo de ser cultural (GEERTZ, 1989). Assim, formas culturais como discursos, posturas corporais e práticas produzem certo tipo de comportamentos e atitudes culturais, com objetivos diversos como, por exemplo, manter as pessoas distantes, aproximá-las, ritualizar eventos, cerimonializar relações sociais, estabelecer regras de convivência, as quais são induzidas, ainda segundo Geertz, por um conjunto de ansiedades sobre a habilidade de realizá-las plenamente.

Ansiedades de interpretação e orientação próprias da condição humana em sua dependência das ordens simbólicas para viver, se interrelacionar no mundo e diferir a quantidade de informação recebida. Importante lembrarmos que os sistemas simbólicos não são adicionados à existência humana, mas são por ela construídos ou nela construídos. Somos criaturas relativamente abertas e flexíveis se comparadas à maioria dos animais que cumprem automaticamente suas pautas de existência. Contudo dependemos de sistemas simbólicos externos - a linguagem e a cultura - para sobreviver.

Assim, ante a perspectiva e o fato da interação social, "há uma preocupação de que não se possa agir com a finesse exigida" (GEERTZ, 1989, p. 402). A elaborada arquitetura cultural, os discursos e práticas conectados, os termos pessoais, os calendários, as regras de etiqueta, tudo isso tanto alimenta como suaviza esse conjunto de ansiedades. Geralmente, o que se receia é que a performance cultural, pública, em seus moldes de encenação, sofra um colapso, e a personalidade do indivíduo penetre dissolvendo sua identidade pública padronizada, ou que o papel desempenhado seja descaracterizado publicamente, 
revelando a fragilidade do indivíduo. De qualquer modo, a subjetividade em questão tem certa forma cultural. Tem, também, uma maneira de habitar tal forma, a qual é reflexiva e ansiosa, em relação às possibilidades das próprias falhas de cada um.

A mídia tem grande importância nos cenários das teatralidades e suas performatividades, pois prolonga a encenação, em abismo. É formadora cultural, difunde e vende cultura, agrega valor cultural. Dissemina e faz política, forja a identidade, molda comportamentos sociais e transforma sociedades sob as sombras de seus holofotes. Dessa feita, também é responsável por mudanças na cultura popular quando altera o imaginário e as crenças dos indivíduos.

Do dito, essa construção reflexiva se insere também no trânsito de categorias pensadas por Patrice Pavis (2000), a partir de práticas cênicas concretas. O autor esboça o conceito de teatralidades plurais dissociado do termo de qualidades abstratas ou essenciais ao fenômeno teatral e vislumbra a possibilidade do uso pragmático de certos procedimentos cênicos para a ampliação do que concebo como teatralidades e performances. Especialmente falo da materialidade espacial, visual, textual e expressiva de escrituras espetaculares específicas.

Pavis apresenta algumas categorias para a compreensão das performatividades e teatralidades: atenuar o real tornando-o estético ou erótico; ser um movimento de choque para se conhecer realidades e compreender o político, assim como as performances, flash mobs, passeatas zumbis; ser um embate para abarcar os regimes ficcionais, tal como a temática apocalíptica zumbi, os quais parecem disputar a primazia de constituição do teatro, ou simplesmente o discurso linear de um narrador tencionado para o final do mito, mas que retorna sempre ao princípio. Pode ser a capacidade de mudar de escala, de sugerir e fabricar o real com a voz, a palavra, o som e a imagem. Pode, inclusive, ser uma categoria que se apaga sob outras formas de performatividades, voltadas para campos extracênicos, culturais, antropológicos, éticos. Portanto, é no trânsito dessas categorias e conceitos que percebo e interpreto a ficcional invasão dos zumbis e suas performances nas realidades cotidianas.

\section{A invasão dos zumbis e seus antecedentes históricos}

Uma grande onda de representações visuais de zumbis invadiu o mundo através dos canais midiáticos. São histórias em 
quadrinhos, jogos de tabuleiro, filmes, games e cartazes. Há, ainda, as performances. Atualmente são comuns festas, flash mobs, - aglomerações instantâneas de pessoas em certo lugar para realizar determinada ação inusitada - passeatas de indivíduos travestidos de zumbis pelas ruas das cidades. Eles cambaleiam, grunhem e dançam, vestidos como mortos-vivos, esfarrapados e maquiados. Em Goiânia, o Zombie Walk foi realizado no Parque Vaca Brava, no dia 2 de novembro de 2011, com a presença de mais de quatrocentas pessoas. A segunda edição, intitulada Dia-Z, aconteceu em dois de novembro de 2012, no mesmo parque (figura 2). Mas quais foram os abalos sísmicos geradores desse tsunami?

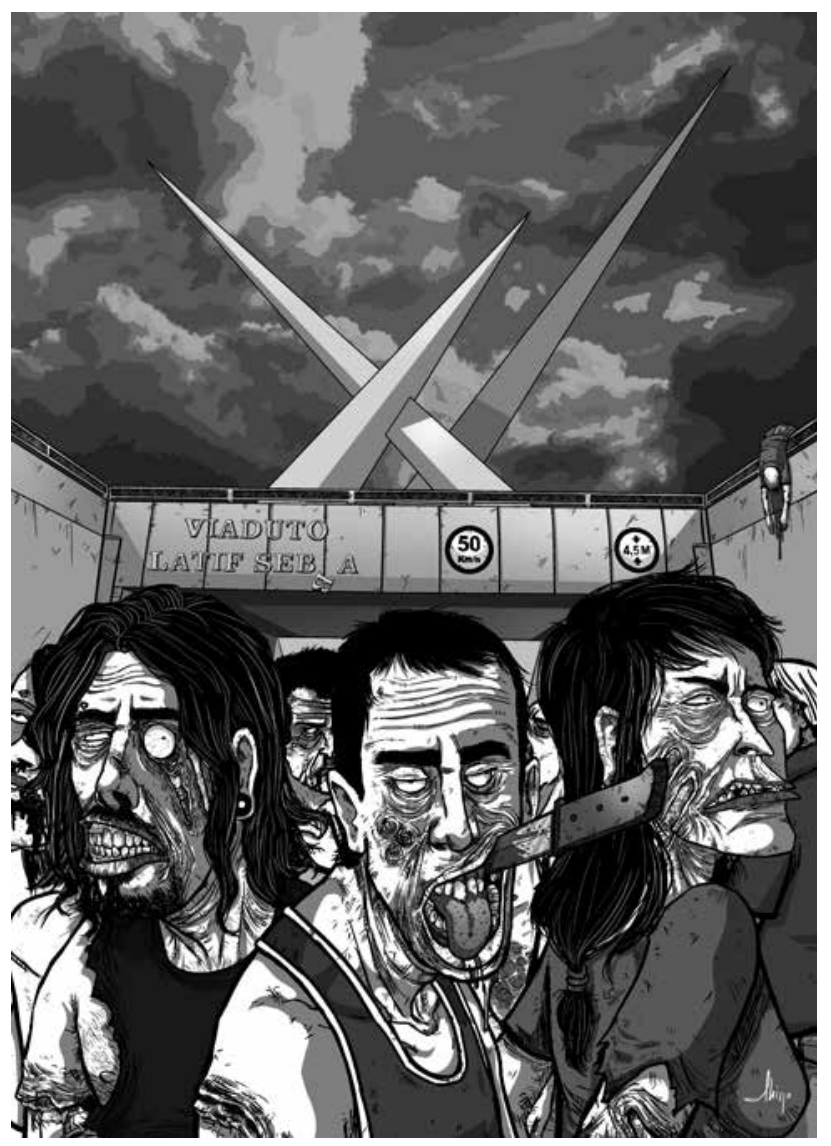

Acredita-se que a série de televisão The walking dead estreada em outubro de 2010, nos Estados Unidos, seja uma entre as muitas placas tectônicas deslocadas. A série narra a história
Figura 2

Thiago Dornellas. Viaduto Latif Sebba, recorte HQ, 2013. Desenho colorido com técnica computadorizada 
de um grupo de humanos tentando sobreviver em um mundo pós-apocalíptico povoado por corpos pútridos de mortos-vivos, zumbis canibais. Em seu primeiro episódio a série registrou recorde de audiência. Foi vista por cerca de 5,3 milhões de espectadores nos Estados Unidos (HUFFPOST BUSINESS, 2013) e é originária de uma história em quadrinhos, publicada nos Estados Unidos pela Image Comics a partir de 2003. Foi criada e escrita por Robert Kirkman e o desenhista Tony Moore, substituído por Charlie Adlard a partir da edição número 7. Contudo Moore continuou a desenhar as capas até a edição número 24 . Durante seu lançamento, a história em quadrinhos não obteve grandes vendas, mas ganhou grande popularidade com o tempo. Em 2006, a primeira tiragem da trigésima terceira edição da série esgotou em apenas 24 horas (ASSIS, 2006).

Em 2010 a série ganhou o prêmio Eisner Award, de Melhor Série Contínua, anunciado na San Diego Comic-Com (ASSIS, 2006). O sucesso da série americana é mais um dentre outros anteriores: o filme Warm bodies; história em quadrinhos como Os mortos-vivos, editado em Portugal pela Devir Livraria; mangás lançados no Oriente como Highschool of the dead (2006), criado por Daisuke Sato; videogame como o Plants vc. zombies, lançado em 2009, e jogo de tabuleiro da Z-Man Games em 2010 (ASSIS, 2006). Em 2013, a série estreou na TV aberta do Brasil pela Rede Bandeirantes de Televisão, e a história foi publicada em quadrinhos em forma de encadernados pela HQM Editora.

A despeito do sucesso de The walking dead a partir de 2010, desde os meados dos anos 2000 intensificaram-se as películas sobre zumbis, com o lançamento de filmes como Dawn of the dead, Despertar dos mortos, no Brasil, e 28 days later, traduzido como Extermínio. Depois, vieram outras histórias, como Warm bodies, traduzido no Brasil por Meu namorado é um zumbi, em 2013.

Antecede esse tsunami de zumbis o clip Thriller, sexto álbum de estúdio do famoso cantor e compositor norte-americano Michael Jackson, lançado em 30 de novembro de 1982 pela gravadora Epic/CBS Records. O clip zumbi foi dirigido por John Landis, diretor de Um lobisomen americano em Londres. A maquiagem, a produção, o andar e os passos de dança são, inclusive, referências para os flash mobs atuais. Thriller, por sua vez, faz claras alusões ao clássico A noite dos mortos vivos, de George A. Romero.

Romero formula o conceito apocalíptico da invasão dos zumbis em 1968 e é considerado fundador do gênero, com seu 
filme já mencionado acima. Por sua vez, Romero se apoiou no livro I am legend de Richard Matheson (1954), no qual um sobrevivente solitário, Robert Neville, trava uma guerra contra a população humana transformada em vampiros. Mas Romero não esclarece sobre as causas do apocalipse e substitui os vampiros da produção de Neville por seres esfarrapados, mortos-vivos, que comem os vivos que encontram. Com isso, Romero reinventou o termo "zumbi" na cultura popular diferentemente de seu uso até então habitual. Produções cinematográficas anteriores ao filme de Romero, tais como White Zombi, de 1932, e I walked with a zombie, de 1943, mostravam os zumbis como pessoas vivas, escravizadas, mentalmente, por bruxos praticantes de magia negra, tal como o vodu. As histórias se passavam em cenários imaginários, de lugares exóticos e desconhecidos como o Caribe. O terror despertado pelo filme Night of the living dead movimentou a cena urbana de Pittsburgo/Pensivânia, principalmente a cena em que a menina Karen Cooper, reanimada como um zumbi, devora o cadáver de seu pai.

Há, ainda, uma franquia de mídia mais antiga criada por Shinji Mikami, em 1996, que perdura até o presente com grande destaque nesse gênero, pertencente à empresa de videogames Capcom, intitulada Resident Evil, também conhecido como Biohazard no Japão. Ela é constituída por histórias em quadrinhos, livros, filmes e jogos (figura 3) que constituem uma variedade de coleções, incluindo figuras de ação e guias de estratégias.

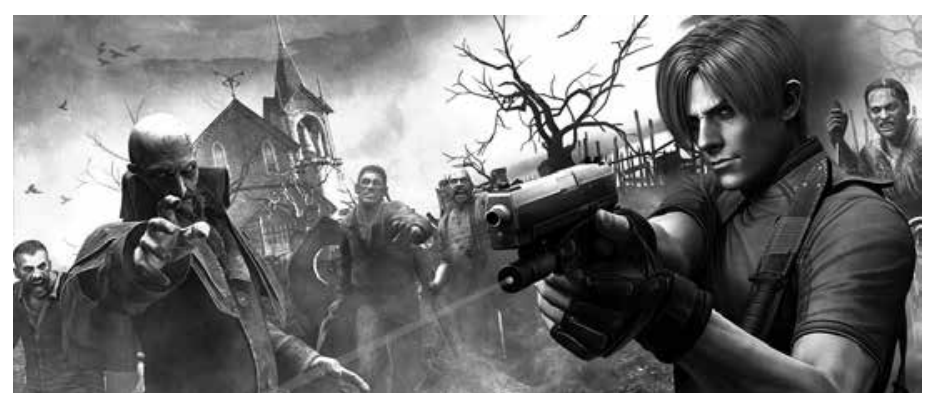

\section{A morte do sujeito e outras desorientações}

O drama vivido pelos poucos sobreviventes ao apocalipse zumbi das histórias em quadrinhos The walking dead, jogos, filmes e seriados para TV trazem um conflito em cada microesfera das diferentes linguagens visuais e seus suportes, que corresponde a um macroespaço social de tensão e jogo entre uma estrutura 
com organização, valores, comportamentos, enfim, de códigos sociais estabelecidos por uma tradição moderna para uma dimensão intersticial dessa mesma estrutura, o pós-moderno.

Victor Turner verificou que, em momentos críticos da sociedade, os dramas sociais evidenciam com mais frequência a intrínseca relação entre ritual e conflito. No processo da vida cotidiana, os dramas emergem uma relação dialética entre a estrutura que representa a vida cotidiana e a antiestrutura, ou seja, aqueles momentos extraordinários definidos pelos dramas sociais. $\mathrm{O}$ autor conceitua estrutura como uma disposição mais ou menos característica das instituições, dependentes entre si, e a organização institucional de posições e de atores que elas implicam (TURNER, 1974, p. 201-202).

Nos produtos midiáticos com a temática zumbi, emerge o drama social pela sobrevivência dos dois grupos, zumbis e alguns poucos sobreviventes humanos. Há conflitos entre eles, mas há conflito também nos pequenos grupos de humanos que ainda se referenciam por meio de uma estrutura, ainda que em desestruturação, por uma caótica antiestrutura zumbi. Nesse limiar os grupos de humanos repensam suas estratégias e as reorganizam para sobreviver.

Segundo Turner, na dialética social há um determinado momento em que a estrutura institui uma antiestrutura, a qual configura um espaço liminar, por excelência do drama social, um momento instituído pela própria sociedade visando lidar com as próprias contradições, conflitos, crises e/ ou problemas não resolvidos que ameaçam ruir as bases da estrutura social. $\mathrm{O}$ autor esclarece que esse momento entre parênteses é uma maneira como o próprio agrupamento social produz um distanciamento reflexivo sobre si mesmo e, em um segundo momento, a antiestrutura tende a contribuir para a revitalização da própria estrutura social. Turner remete ao conceito "liminaridade", de Van Gennep (2011), associado à noção de margem. Van Gennep usa o termo para referir-se a indivíduos "transitantes" ou de passagem de uma posição de status ou lugar para outro, no sentido social e espaço-ritual.

Outro conceito de Turner (1974, p. 161), a "communitas", complementa sua noção de liminaridade e lhe é inseparável. A communitas é uma relação estabelecida entre indivíduos concretos, históricos, idiossincráticos, não fragmentada em funções e posições sociais como em uma estrutura social, tradicional. De todo modo, essas relações e ações correspondem a desempenhos sociais, aqui considerados por mim como performances culturais. 
Historicamente, a narrativa para o apocalipse zumbi carrega, desde o filme Night of the living dead, - baliza do gênero fortes relações com o turbulento cenário social que os Estados Unidos viviam na década de 1960 - o descontentamento com a Guerra do Vietnã (1955-1975). Esse descontentamento ampliou-se, decada após década, e se evidenciou em 2003, com a Guerra do Iraque, conjuntamente com o aumento dos produtos midiáticos sobre o gênero zumbi (LAURO; EMBRY, 2008). Foi uma forma que as pessoas encontraram de se manifestar, pelo fato de se não se sentirem ouvidas pelo governo Bush (de 2001 a 2009). Esse tipo de encenação não se enquadra na diversidade de produtos de consumo voltados para o entretenimento, que abastece o apreço pelo gênero, e não finda em si. Há ainda outras manifestações populares, tais como cartazes anônimos afixados nas vias públicas americanas, com teor de humor. Neles se lê: "Zumbis não te amam! Mire na cabeça!" (figura 4).

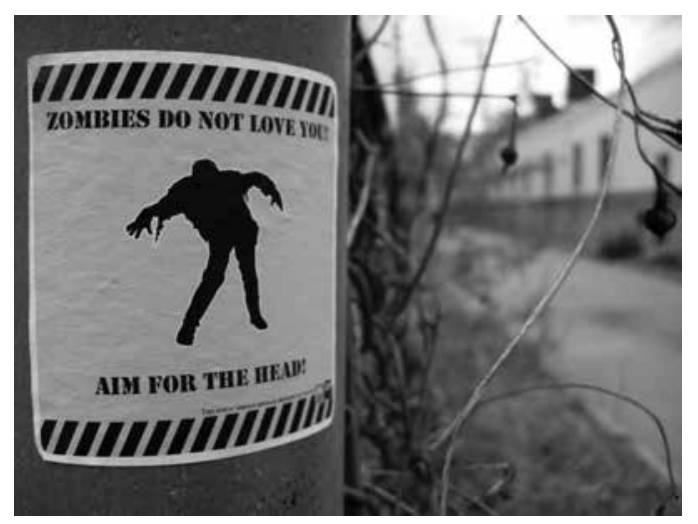

Nicole Ramage, uma fã de The walking dead, afirma: "I think that the more society feels like a drone to the government, economics, or anything else in their life, the more they feel like zombies and zombie role-playing/entertainment begins to increase" (RIOS, 2013).

Falta, aos personagens zumbis e humanos, profundidade. O zumbi é somente um invólucro daquilo que se assemelha ao humano. Uma representação. Por sua vez, os personagens humanos não têm tempo nem espaço para se preocuparem com nada mais do que salvar sua própria pele, ou melhor, carne da carnificina zumbi. É o que nos serve como metáfora para refletirmos sobre a ausência de profundidade em nossa época conjuntamente com o enfraquecimento da relação com a História pública e as novas formas de temporalidade privada.
Figura 4

Cartaz alertando para a sobrevivência zumbi, em rua residencial nos E.U.A. 
Nas histórias em quadrinhos, jogos de tabuleiro, games, na série The walking dead, enfim, todas as performances de seus personagens, não há partilhamento de uma história comum, mas histórias fragmentadas de indivíduos fragmentados pelo apocalipse zumbi. Não obstante algumas poucas diferenças entre as histórias que perpassam as diferentes linguagens visuais e performáticas dos conflitos entre zumbis e humanos, ambos são deslocados espacialmente e simbolicamente de seus lugares e ambos se preocupam somente com sua própria condição - básica - de sobrevivência. Mas a crise atual é também uma crise de orientação dentro de um mundo não interpretável. Os modelos complexos de sujeito, imersos na profundidade subjetiva, que abarcavam as realidades psíquicas e mundo externo são agora substituídos pela rasura da superfície.

Os personagens do apocalipse zumbi encenam em uma paisagem constituída por ruínas e/ou natureza que não trazem em si nenhuma segurança ou proteção e os aspectos centrais das histórias constituem um pesadelo geertziano, desordenador, desorientador, exaurido de significado e afeto. Os personagens zumbis performam os sujeitos pós-modernos desorientados no tempo pelo esfacelamento da História? Vagam em espaços labirínticos, sem memória como experiência vivida, “não lugares" (Augé, 1994)?

Na falta de um vocabulário com profundidade e complexidade subjetiva de suas vidas emocionais, os indivíduos são reduzidos a uma massa anônima e padrões de consumo. Estão sujeitos às explosões emocionais incoerentes e performadas em sujeitos cambaleantes, mortos-vivos, grunhidos, euforias dos flash mobs e passeatas?

Enquanto o grupo dos zumbis encena, nos produtos midiáticos, a si mesmos como mais um só outro membro do grupo, se movimenta na indiferença e na mais obscura ação do "poder sem autoridade" (SENNETT, 1998, p. 114), os humanos sentem a falta de relações humanas duradouras e propósitos duráveis; praticam, como último recurso, os desempenhos das habilidades de "ação profunda" e chegam até a insinuar as performances das "máscaras da cooperatividade" (p. 112). Máscaras frágeis, que caem quando há alguma ameaça à sobrevivência de qualquer um dos humanos.

Há, nesse conjunto de encenações zumbis, uma clara evidência da necessidade de ferramentas conceituais, cognitivas e simbólicas, para enfrentar o drama social, assim como propõe Jameson (1997), bem como reorientar e reconstituir o sujeito dentro desse novo regime, chamado pelo autor de 
pós-modernidade. Mas é fato que nos faltam coerência e ressignificação por meio de um exercício subjetivo de reflexibilidade e crítica que monitore a relação eu-mundo na contemporaneidade. Fato constatado em observação empírica sobre a nossa realidade cotidiana. Precisamos desenvolver outra subjetividade. Não uma subjetividade incorporada da cultura dominante que nos transforma em zumbis. Mas contracorrentes de subjetividade tanto como de cultura. Eis nosso desafio.

\section{Referências}

ASSIS, Érico. Edição 33 de The Walking Dead esgota em 24 horas. Omelete, 2006. Disponível em: http://omelete.uol. com.br/quadrinhos/edicao-33-de-the-walking-dead-esgota-em-24-horas/. Acesso em: 03. abr. 2013. . Conheça os vencedores do Eisner Awards 2010. Omelete, 2010. Disponível em: <http://omelete.uol.com.br/ quadrinhos/conheca-os-vencedores-do-eisner-awards-2010/>. Acesso em: 14 abr. 2013.

AUGÉ, Marc. Não-Lugares: introdução a uma antropologia da supermodernidade. Campinas: Papirus, 2010.

GEERTZ, Clifford. A interpretação das culturas. Rio de Janeiro: Guanabara Koogan, 1989.

GOFFMAN, Erving. A representação do eu na vida cotidiana. Petrópoles, RJ: Vozes, 2011.

HUFFPOST BUSINESS. 10 ways zombies became a $\$ 5$ billion industry: 24/7 Wall St. April, 28. 2013. Disponível em: <http:// www.huffingtonpost.com/2011/10/25/zombies-economy-pump-5-million_n_1030569.html\#s432036\&title=Zombie_ Books_and $>$. Acesso em: $10 \mathrm{abr} .2013$.

JAMESON, Fredric. Pós-modernismo: a lógica cultural do capitalismo tardio. Trad. Maria Elisa Cevasco. São Paulo: Ática, 1997.

LAURO, Juliet; EMBRY, Karen. A zombie manifesto: the nonhuman condition in the era of advanced capitalism boundary 2 . Spring, v. 35, n. 1, p. 85-108, 2008. Disponível em:<http:// boundary2.dukejournals.org/content/35/1/85.full.pdf.>. Acesso em: 02. maio 2013.

PAVIS, Patrice. Vers une théorie de la pratique théâtrale: voix et images de la scène. France: Septentrion, 2000.

RIOS, Taylor. Research says The Walking Dead and zombie movie fans may be unhappy. Examiner.com. Zombies. March 12, 2013. Disponível em: <http://www.examiner.com/ar- 
ticle/research-says-the-walking-dead-and-zombie-movie-fans-may-be-unhappy>. Acesso em: 02. maio 2013.

SENNETT, Richard. A Corrosão do caráter: as consequências pessoais do trabalho no novo capitalismo. Trad. Marcos Santarrita. Rio de Janeiro: Record, 1998.

TEMPERTON, Rod. Thriller. Álbum de estúdio. Duração: 42hımin. Califórnia/Los Angeles: Westlake Recording Studios, 1982.

TURNER, Victor. O processo ritual: estrutura e anti-estrutura. Petrópolis/RJ: Vozes, 1974. . Dramas, campos e metáforas. Niterói, RJ: Eduff, 2008.

VAN GENNEP, Arnold. Ritos de passagem. Petrópolis, RJ: Vozes, 2011.

Recebido em: 24/09/13

Aceito em: 05/10/13 


\section{SAINY C. B. VELOSO \\ sainyveloso@yahoo.com.br \\ É doutora em História Cultural e mestra em Artes pela UnB; especialista em Linguagens Artísticas e licenciada em Educação Artística pela FA/ FBT-Brasília. É professora da Faculdade de Artes Visuais e atua no pro- grama de pós-graduação Performances Culturais, da Escola de Música e Artes Cênicas -EMAC/UFG. Coordena o grupo de pesquisa Imagem e História Cultural/CAPES. Bolsista pos doutoral CAPES, em Cultura y Sociedad -IDAES/ Universidad de San Martin, Buenos Aires.}

